\title{
Board 18: Social Network Analysis of In-Group Biases with Engineering Project Teams
}

\section{Nitzan Navick, California State University, Channel Islands}

Nitzan Navick obtained a B.A. in Psychology from California State University Channel Islands. She is now a post-bacc student working on a new, original study and will be entering the MA/PhD in Communication Program at UCSB in Fall of 2019. Currently, she works as a grant coordinator for Projects iPath and Adelante at CSU Channel Islands, two Title V grant sub-awards dedicated to increasing the 4-year college attendance rate among community college students in Ventura County - particularly students from historically underserved groups. Her academic and research interests include team processes; virtual teamwork; subjective states' effects on collaboration in computer mediated settings; and network analysis.

\section{Dr. Megan Kenny Feister, CSUCI}

Megan Kenny Feister is an Assistant Professor of Organizational Communication at California State University Channel Islands. She previously held a postdoctoral research position working on her grant funded research in Engineering Projects in Community Service at Purdue University. She is a recipient of the Purdue Research Foundation dissertation grant and co-wrote a National Science Foundation grant for her dissertation and postdoctoral work in Organizational Communication at Purdue. Her primary research interests include collaboration and innovation; negotiations of expertise in team-based organizational work; team processes and decision-making; ethical reasoning, constitution, and processes; engineering design; technology and its impacts on organizational and personal life; and network analysis. 


\title{
Social Network Analysis of In-Group Biases with Engineering Project Teams
}

\begin{abstract}
This study explores the relationship between friendships of engineering students on project teams within a classroom setting and how their perceptions of each other create in-group biases throughout the class. Using Social Network Analysis (SNA), an analysis that enables researchers to examine relationships among members of a given group, we were able to identify distinct ingroups, otherwise described as groups of students with similar social identities. Survey data about participants were collected twice over the course of a semester that identified their designated project team and demographics. We paid particular attention to participants' perceptions of, and reliance on, a teammate's competencies as our visual representation of the data indicated that in-groups were rather distinct in these conditions. Attributes including age, sex, ethnicity, racial identification, year, and designated project team were drawn from the demographic portion of the SNA surveys and assigned to each participant to determine if relationships and communication may be impacted by these characteristics. The ability to pinpoint where in-groups begin and end, and the factors that may aid in their formation, is crucial when aspiring to better understand team dynamics. By identifying reciprocal ties and the way they affect perceptions and willingness to rely on others, a more cohesive network can be established throughout the whole class by therefore minimizing any potential knowledge sharing disparities and improving work efficiency. Thus, the findings from this study can be utilized to encourage increased knowledge sharing.
\end{abstract}

\section{Introduction}

Having friendships within one's organization has, at times, proven to be conducive to both work environments and individual welfare. In their research on interpersonal relationships of personnel, Methot, Podsakoff, Lepine, and Christian [1] found that workplace and organizational friendships have been shown to have positive impacts on some individuals' happiness and effectiveness. A number of employees who reported having friends within their organization, for example, appeared to benefit from higher levels of productivity alongside job satisfaction and retention [1]. However, these friendships may often blur boundaries between objective professionalism and subjective favoritism. Even within a seemingly cohesive organization, subgroups may emerge when the lines between professional relationships and intimate relationships begin to overlap. This becomes an issue of intergroup relations. In-group bias, a phenomenon explored by social psychologists asserting that human beings have the inclination to favor their exclusive groups of shared interests and/or identity [4], may likely result in the unfair judgment of members both within and outside of the in-group respectively. Those who exist within the in-group may be judged less harshly, have their shortcomings attributed to situation rather than disposition, and potentially, be highly praised for abilities in which they are realistically mediocre by other in-group members. Out-group members may, therefore, be at risk of false or unfair evaluation. This could potentially result in a disruption of communication and as such the sharing of resources and knowledge within organizations that may limit the progress of project-team based assignments. 
This paper attempts to identify the formation of in-groups within a class of engineering undergraduate students by exploring how they perceive their friends' competencies. Additionally, this study aims to examine how perceptions of competencies may affect in-group and out-group member's willingness to rely on one another within the class in hopes of helping educators mitigate the effects of in-group biases within a team.

\section{Literature}

\section{Interruption of Knowledge Sharing In Interdisciplinary Organizations}

Communication is critical for any project to progress. Inevitably, team members can learn from one another, but also from others. However, interdisciplinary project teams in a larger class setting are at serious risk for in-group biases. According to Almeida and Soares [2], differentiation within these types of organizations creates a lack of uniformity in the organization's structures, processes, practices, and products. Due to the existence of various disciplines and rituals, the organization becomes fragmented and thus, so does its knowledge sharing. Information is therefore trapped in an "informational limbo" [2] meaning it is out of reach and therefore not being utilized. In-group biases strongly facilitate this "informational limbo" by creating psychological communicative barriers.

To prevent phenomena like the findings of Zhu [8] and Schulz-Hardt, Frey, Luthgens, and Moscovici [7] it is important to identify in-groups in order to merge them promptly. As such, this study utilizes methodologies such as social network analysis and statistical computation of selfreported, rank-order survey data collected by Kenny Feister, Zoltowski, Buzzanell, Torres [10] to classify in-groups. We hypothesized that by constructing a sociogram composed of participants' demographic data and participants' reported perceptions of and willingness to depend on their classmates technical, project-specific, and ethical competencies in-groups will be visually identified through tie reciprocity.

In addition, based on the premises discussed by Almeida and Soares [2], this study pursues information regarding the demographic differences among the class of engineering undergraduates that lead to disproportionate communication of various knowledge. The target goal may allow educators to understand the potential causes of student's misconceptions of one another and increase intergroup communication for the benefit of each team's project.

\section{Methods}

\section{Participants}

Participants consisted of 29 engineering students between the ages of 18 and 22 attending a large Midwestern university. Participants were enrolled in a lab section at the university and were assigned to project teams to work on 6 different products for a community partner. Although the participants could indicate preferences as to which project they would like to work on, they may not have been assigned to their first choice if there were too many other students indicating the same preferences.

The majors reported were as follows: mechanical engineering, biomedical engineering, electrical engineering, first year engineering, industrial engineering, chemical engineering, materials 
engineering, interdisciplinary engineering, agricultural engineering, and civil engineering. 26 of 29 participants identified as Caucasian while 3 participants identified as Asian or Pacific Islander. Other demographics collected included the number of years at the university, the number of years on participants' respective project, what project they were working on, and if they had a formal role within the team.

\section{Materials and Procedures}

SNA rank-order survey data by Zoltowski, Oakes , Buzzanell, Zhu, Kenny Feister [9] were collected twice over the course of a semester that identified each participant's designated project team and demographics such as age, gender, ethnicity, year at the university, and position on the team. Relations were assessed through a roster method, in which participants ranked each of their classmates on a Likert-type scale across seven relations: Q1. I work with this person regularly (e.g. every class meeting; sometimes outside of class time), Q2. I can rely on this person to complete a task he or she agreed to do, Q3. I would feel comfortable sharing my personal problems and difficulties with this person, Q4. I can rely on this person to have the technical competence needed to get the task done, Q5 I can rely on this person to have the project knowledge needed to get the task done (non-technical), Q6. I would go to this person if I had a serious ethical concern about the project, Q7. I consider this person a friend.

In order to map directional ties and tie reciprocity, raw scores from the surveys were converted to binary matrices by determining the median of the total responses of each participant and converting all scores at or above the median to 1 and scores less than the median to 0 . Sociograms were generated for technical competence, ethical competence, and project-specific competence for both times of survey data collection.

Attributes including age, sex, ethnicity, major, year, and formal roles within the team were drawn from the demographic portion of the SNA surveys and assigned to each corresponding participant to determine if relationships and communication may be impacted by these demographic characteristics. Pseudonyms were given to each participant to identify to which project team they belonged. Each team was given pseudonyms with matching initials and identical last names (e.g. Amelia Abrams, Albert Abrams, Ava Abrams). Tie reciprocity was examined in relation to both the demographic data and the general report of ties to determine related patterns.

In addition, Pearson QAP correlations, correlations across two square matrices and assess frequency of random measures, were run on matrices of the raw scores reported on the surveys to determine how strongly perception of friendship, hypothesized to be the primary relation accounting for reciprocal ties, is related to all other relations over two periods of survey data collection during a single semester. For the purpose of this study, particular attention was paid to correlations between perception of friendship and relations measuring their confidence in competencies of others (e.g. technical competence, project competence, ethical competence).

\section{Results}

Sociograms drafted for each survey question were assigned attributes. No observable relationship could be found between sex, major, and ethnicity in relation to any of the perceptions from the SNA survey data as there were few patterns participants of those demographics having recurring 
reciprocal ties. Additionally, 14 different majors were reported and were split relatively evenly among 29 participants. As a result, the majors among them were too varied and therefore showed no noticeable patterns. Finally, of the 29 participants, only 3 identified as an ethnicity other than Caucasian. Therefore, non-Caucasian ethnicities were underrepresented in the data and thus resulted in no conclusive outcomes. However, there appeared to be a notable relationship between years at the university and ties of perceived competencies. Fourth year students appear to have the most reciprocal ties in both friendship and all three conditions of perceived competence. As a result, a sociogram for each period of survey data collection was generated for perception of friendship.

$*_{\text {Black }}=$ missing data Red $=1^{\text {st }}$ year $\quad$ Yellow $=2^{\text {nd }}$ year $\quad$ Green $=3^{\text {rd }}$ year Blue $=4^{\text {th }}$ year

Figure 1: Friendship Time 1

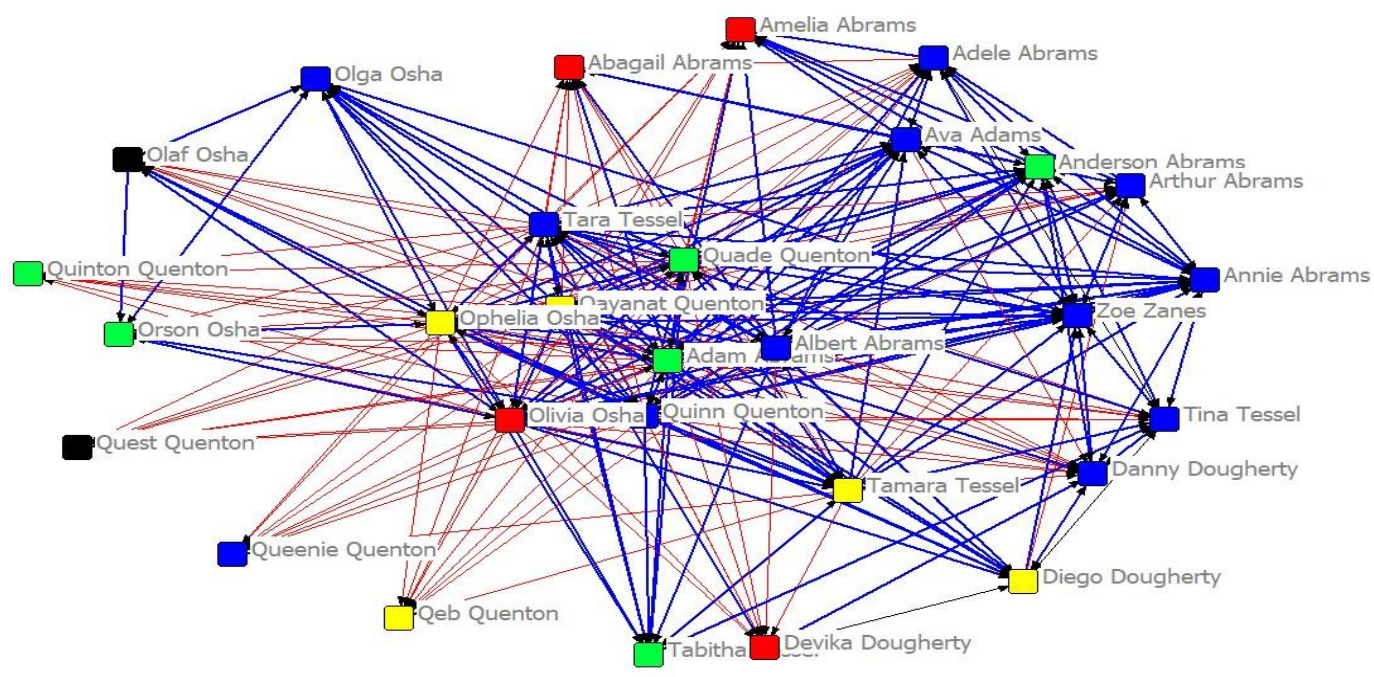

Figure 2: Friendship Time 2

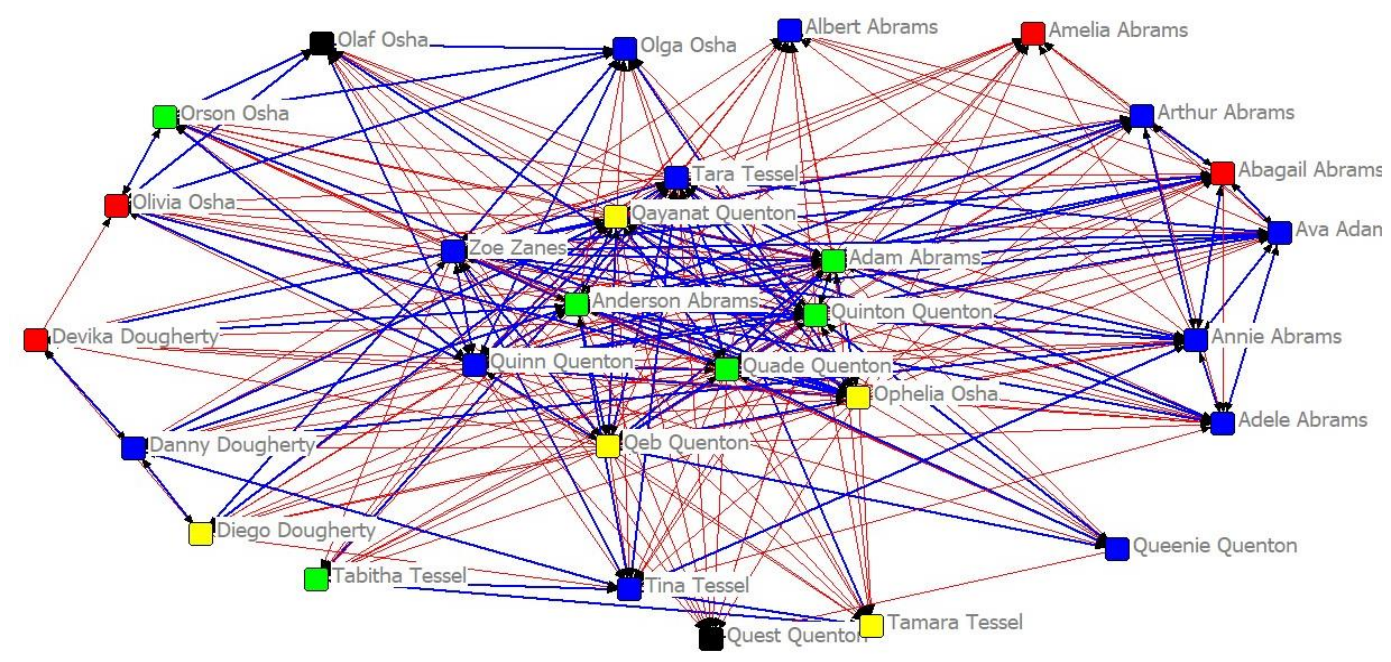


From the first point of survey data collection, and even more so over time, it is clear that there is a high volume of reciprocal ties between members of the same year at the university who consider each other friends, even across project teams. Thus, this attribute is believed to be the dividing factor among this class. As such, each individual year at the university was isolated and unpacked sociograms were generated to show how each year reported their willingness to rely on their classmates' competencies

Figure 3: Technical Competence Time 1 Whole-Network

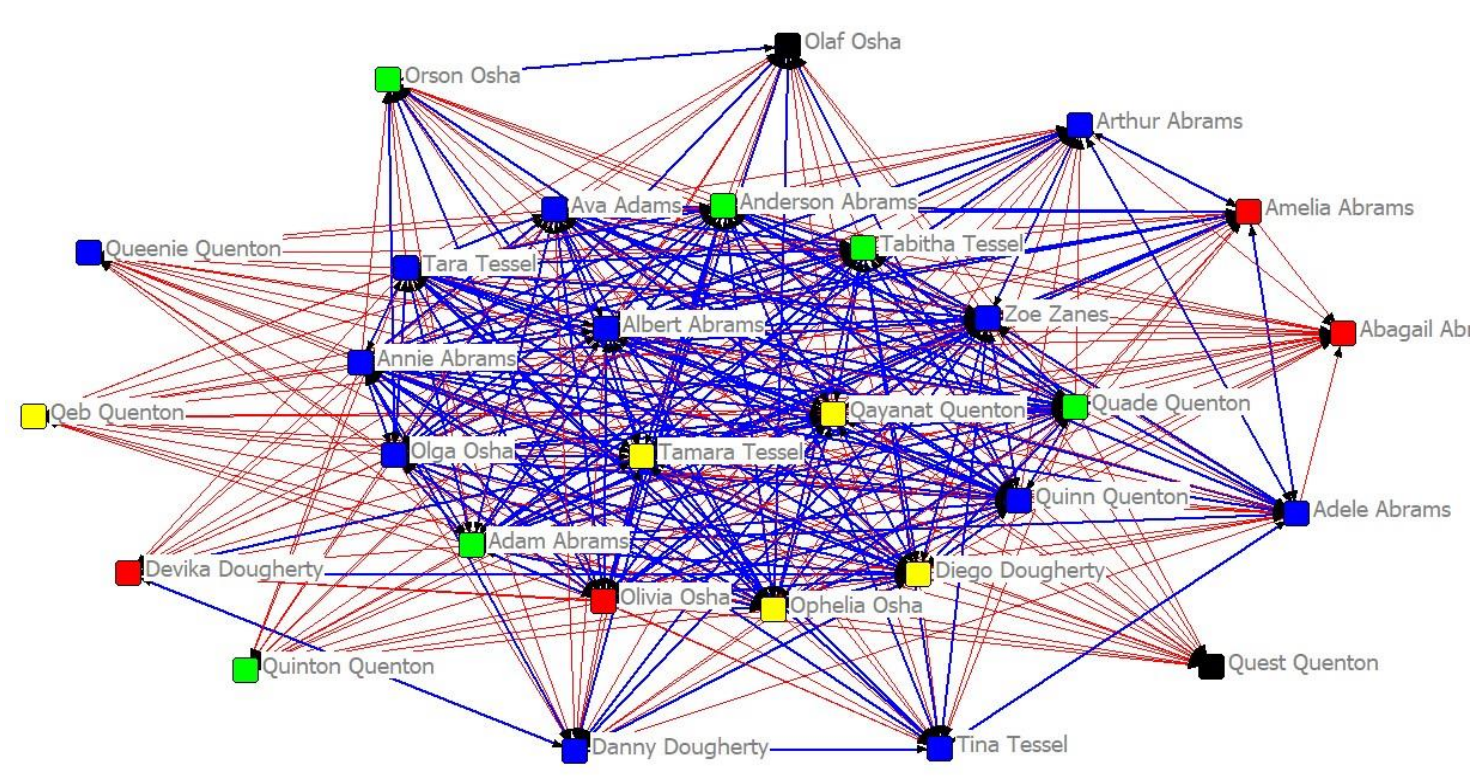

Figure 4: Technical Competence Time 2 Whole-Network

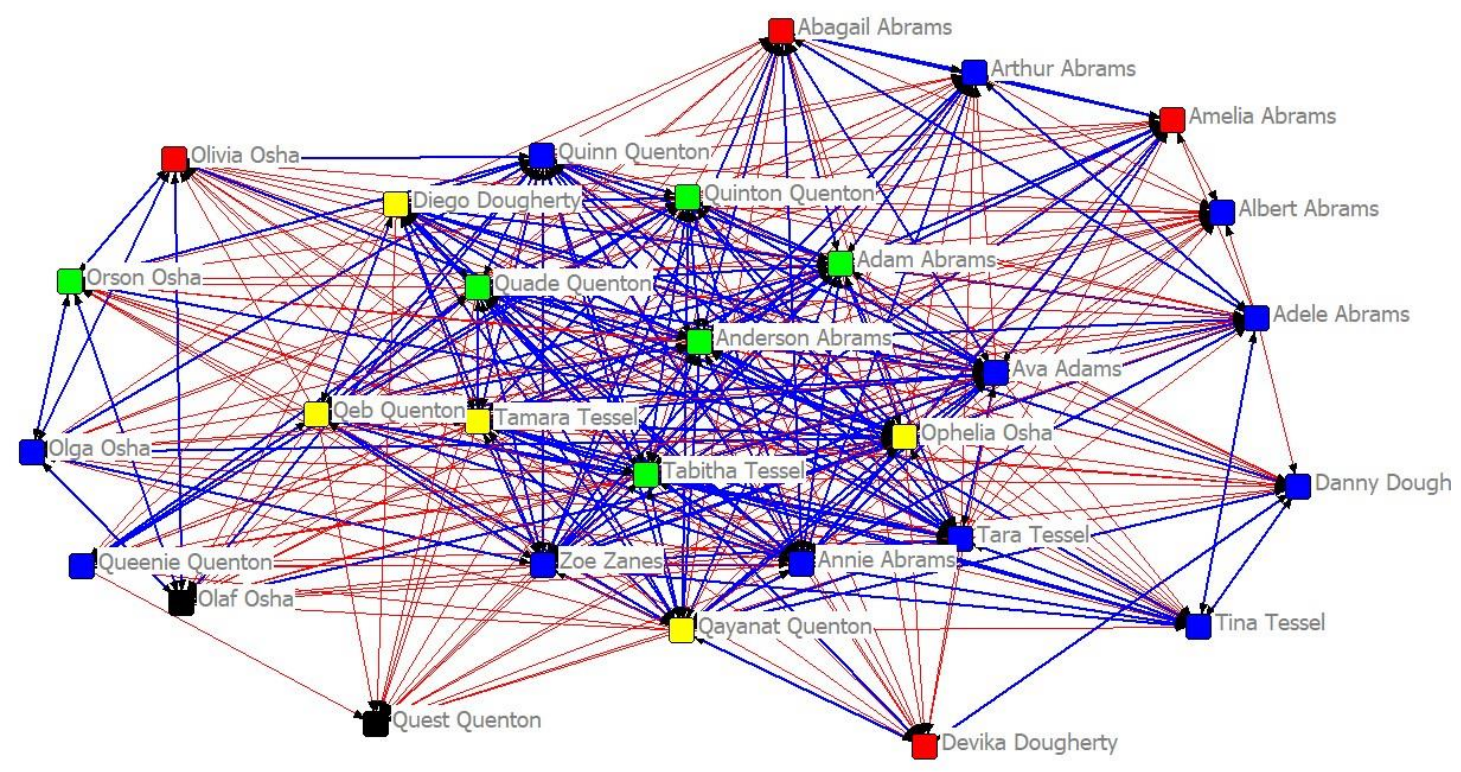


Figure 5: Technical Competence Time 1 Isolated by Year at University
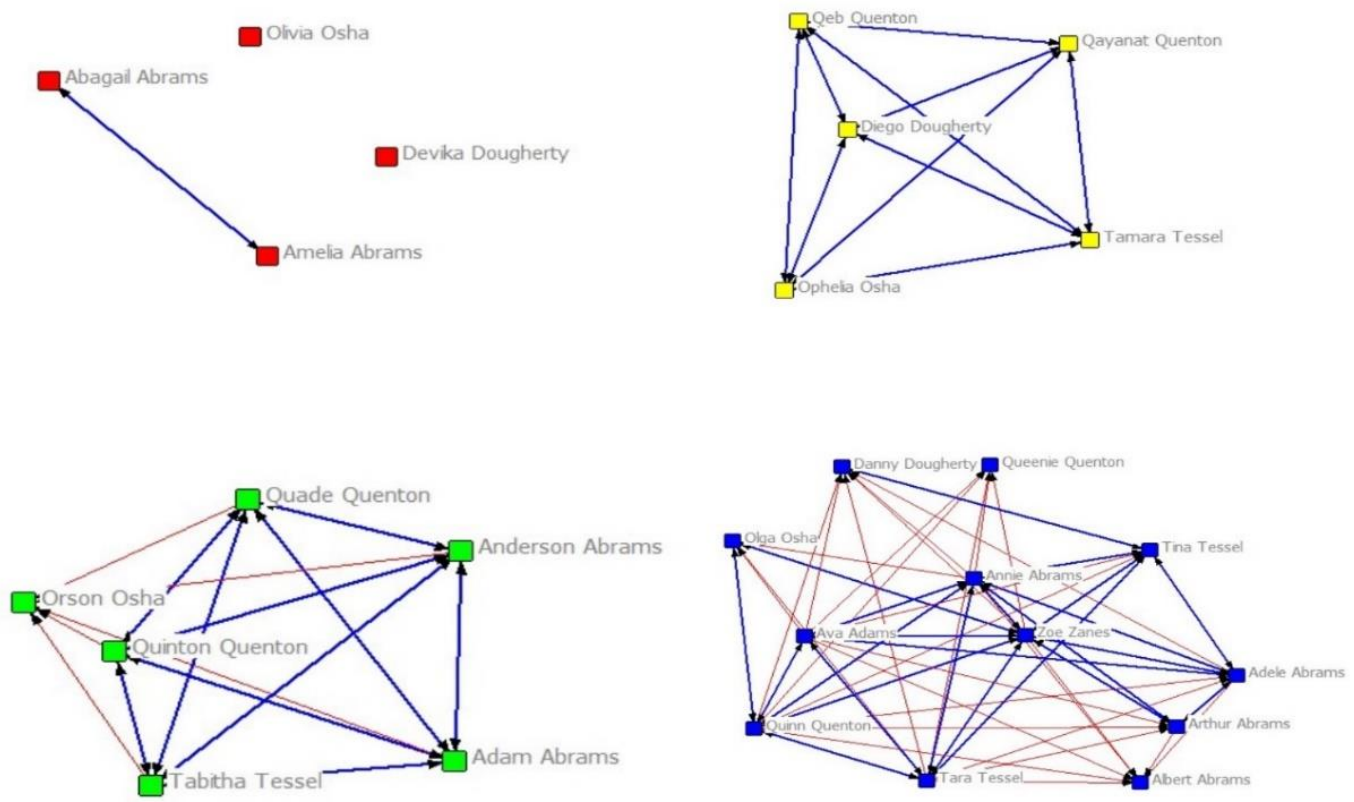

Figure 6: Technical Competence Time 2 Isolated by Year at University
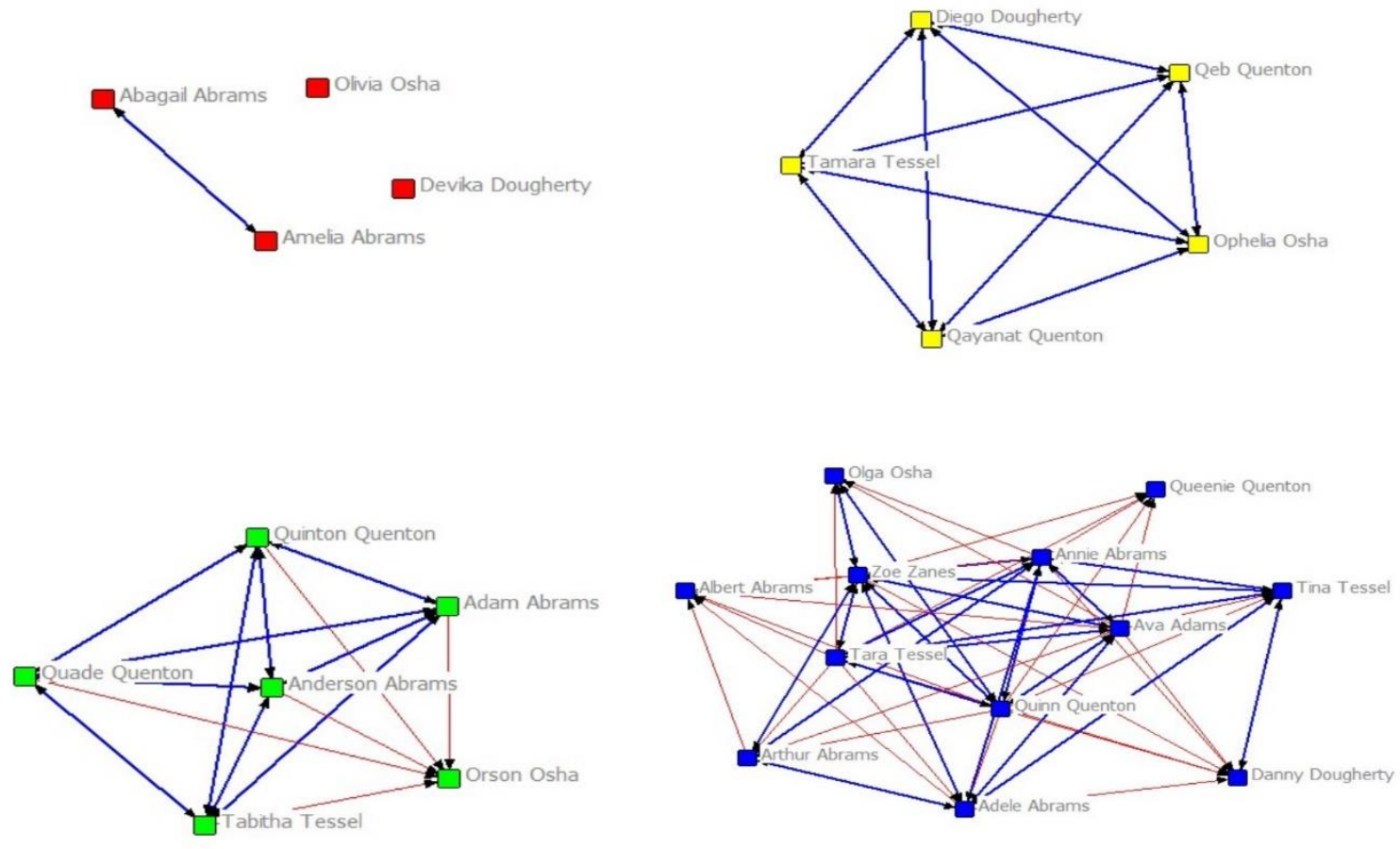
Figure 7: Project Competence Time 1 Whole-Network

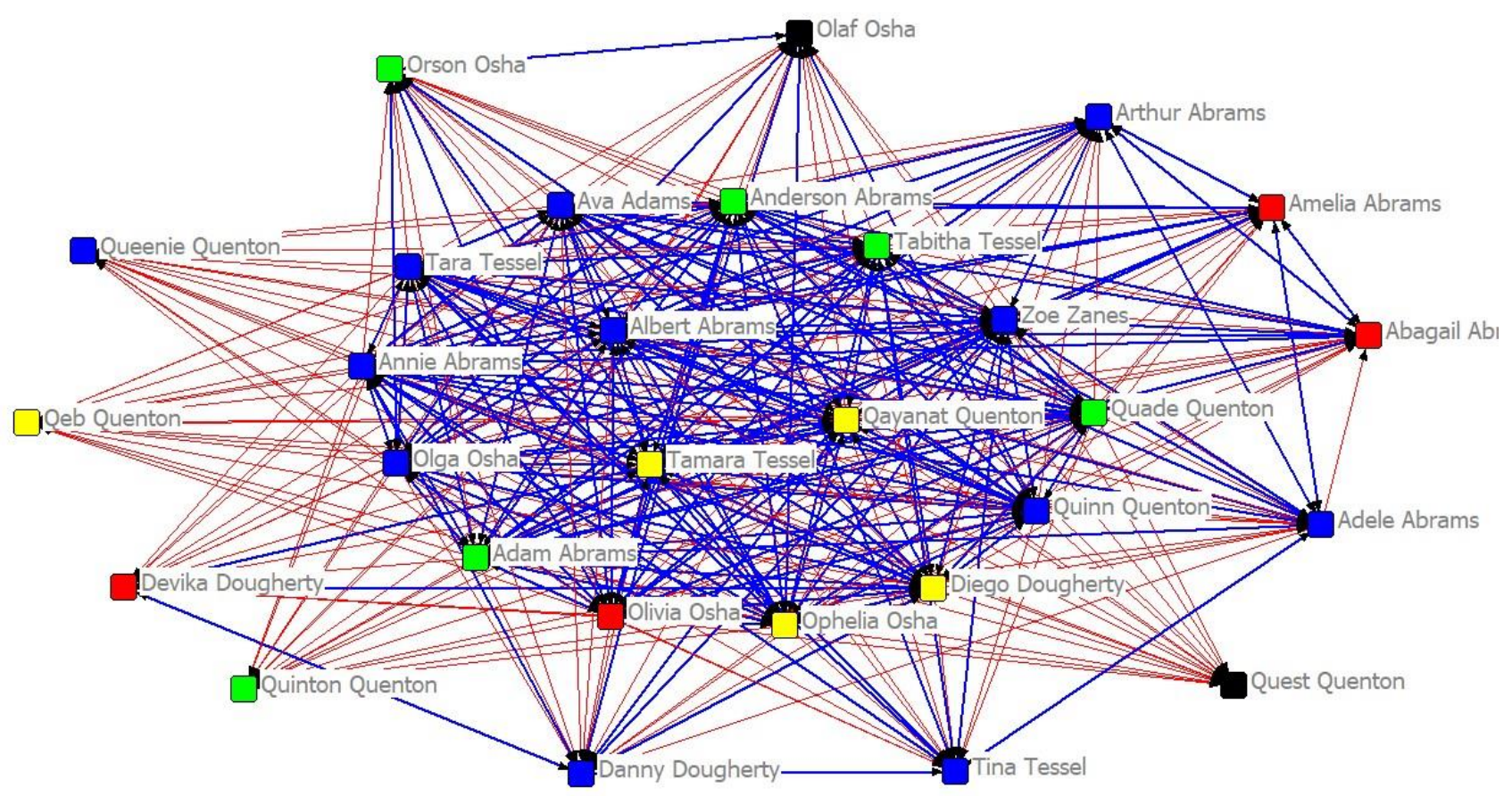

Figure 8: Project Competence Time 2 Whole-Network

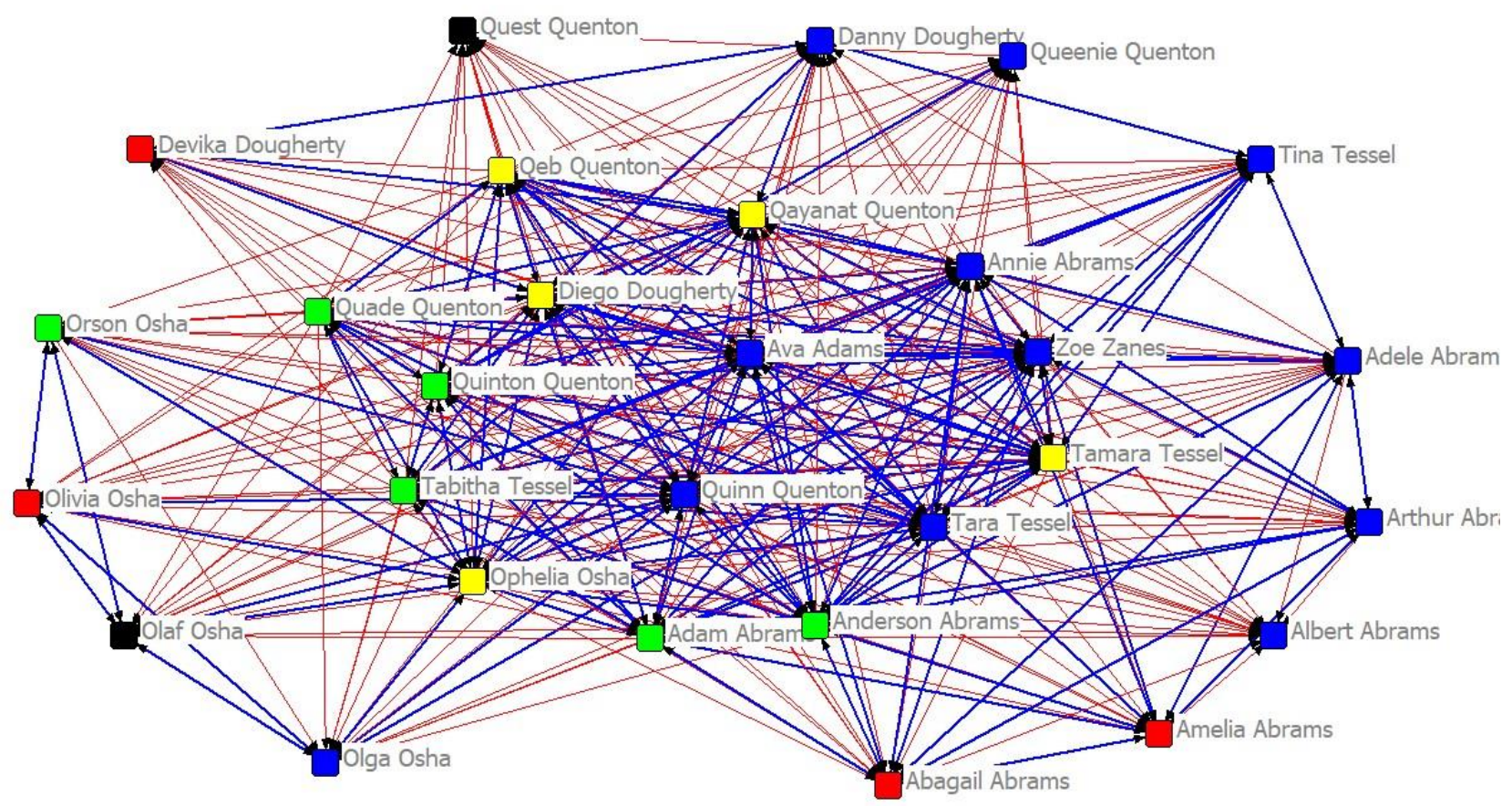


Figure 9: Project Competence Time 1 Isolated By Year at University
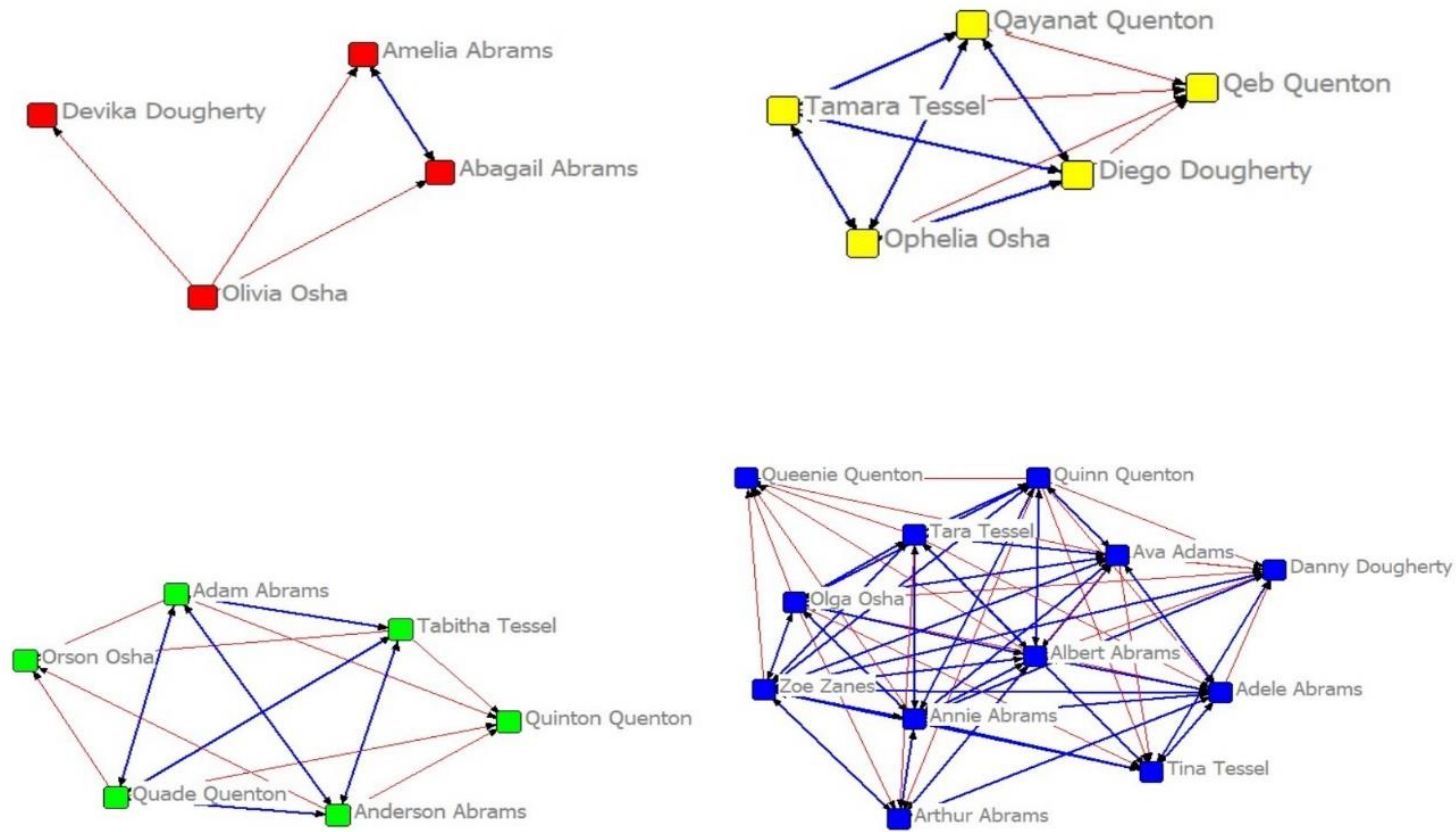

Figure 10: Project Competence Time 2 Isolated by Year at University
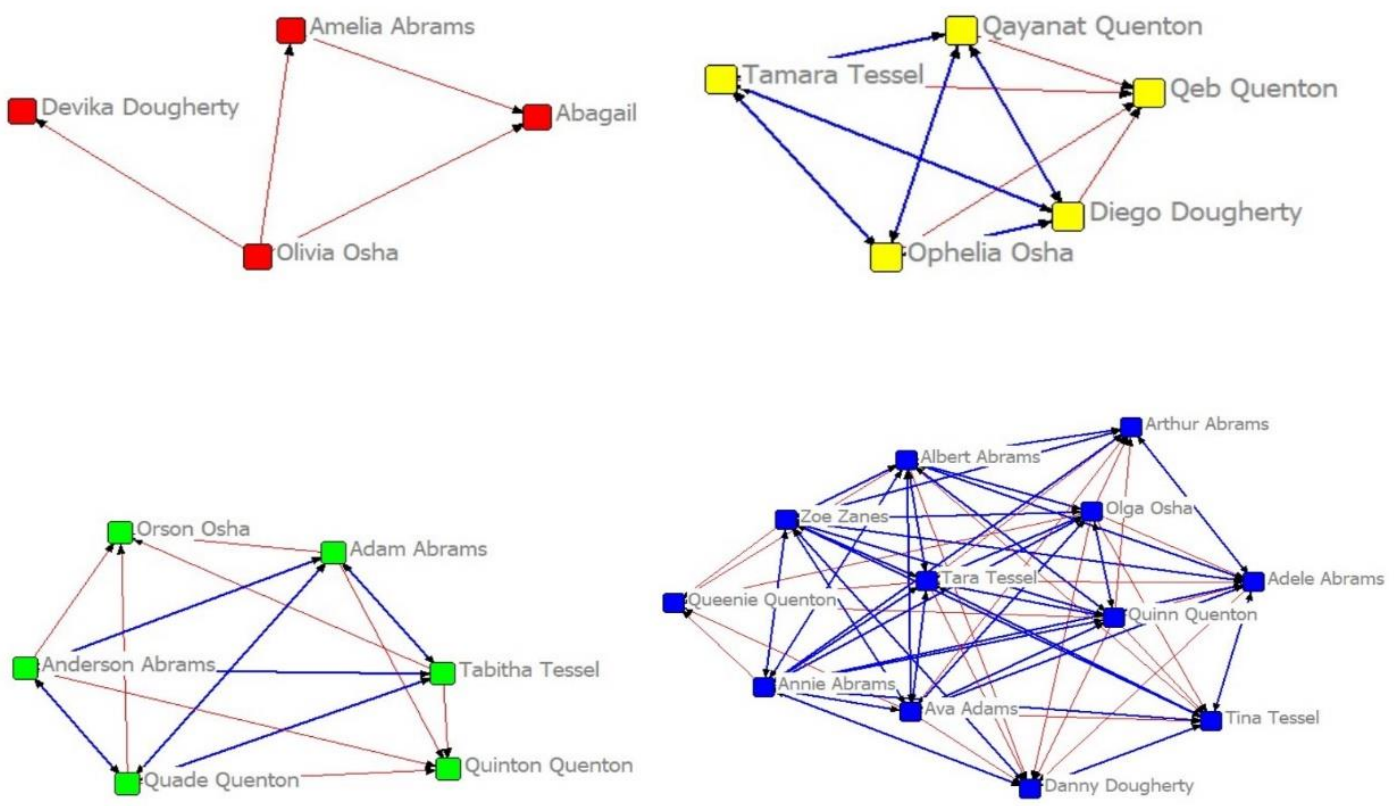
Figure 11: Ethical Competence Time 1 Whole-Network

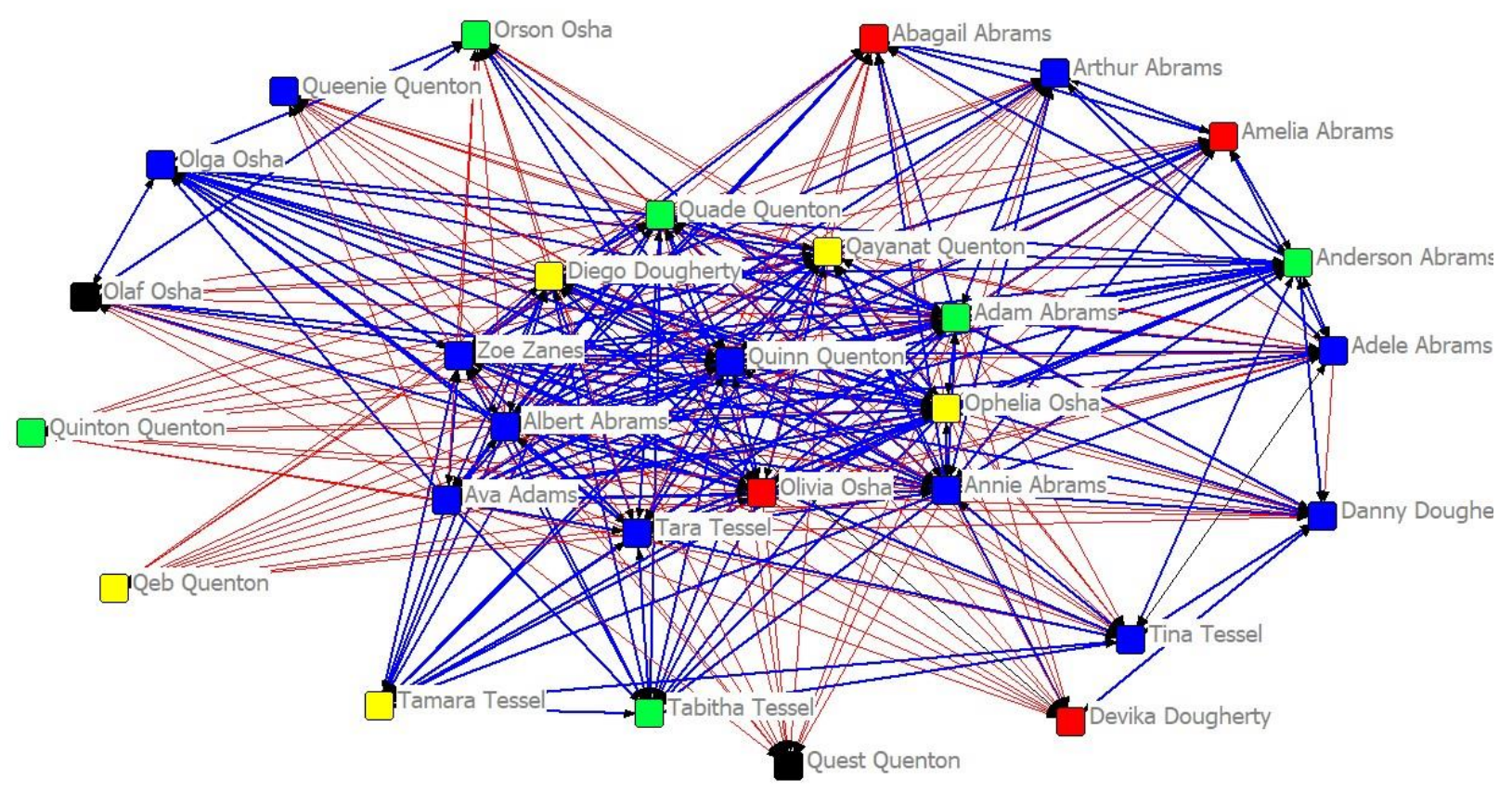

Figure 12: Ethical Competence Time 2 Whole-Network

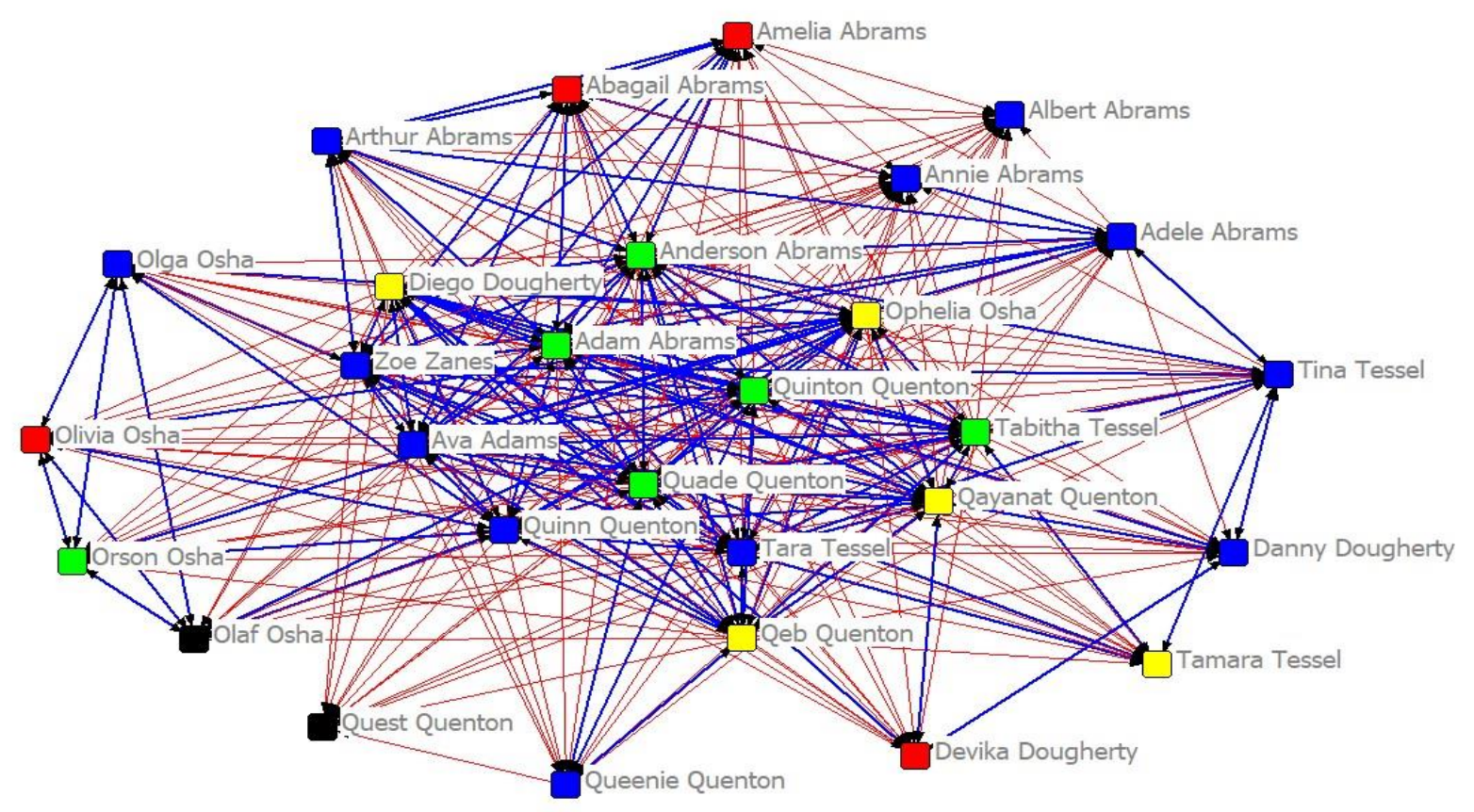


Figure 13: Ethical Competence Time 1 Isolated by Year at University
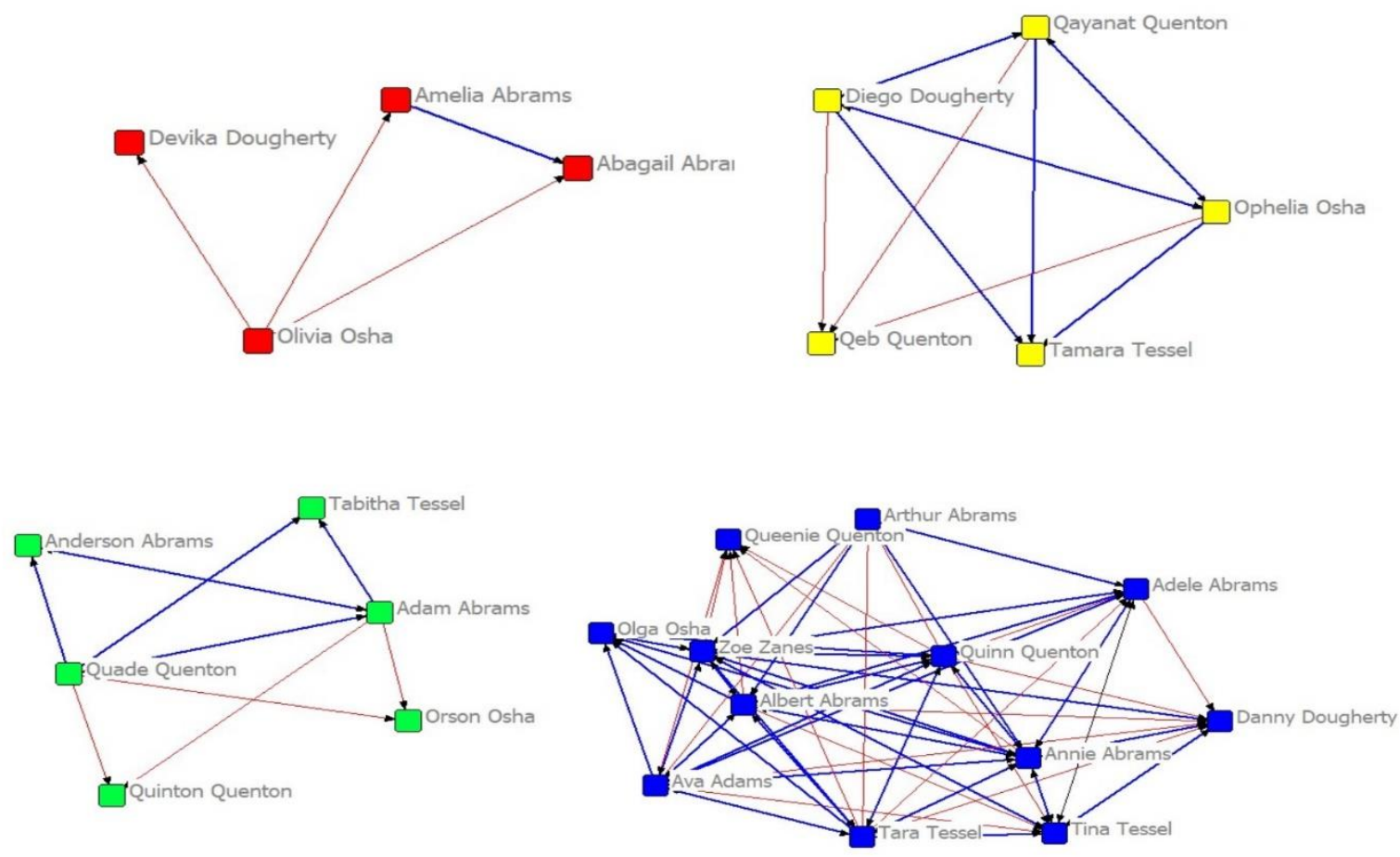

Figure 14: Ethical Competence Time 2 Isolated by Year at University
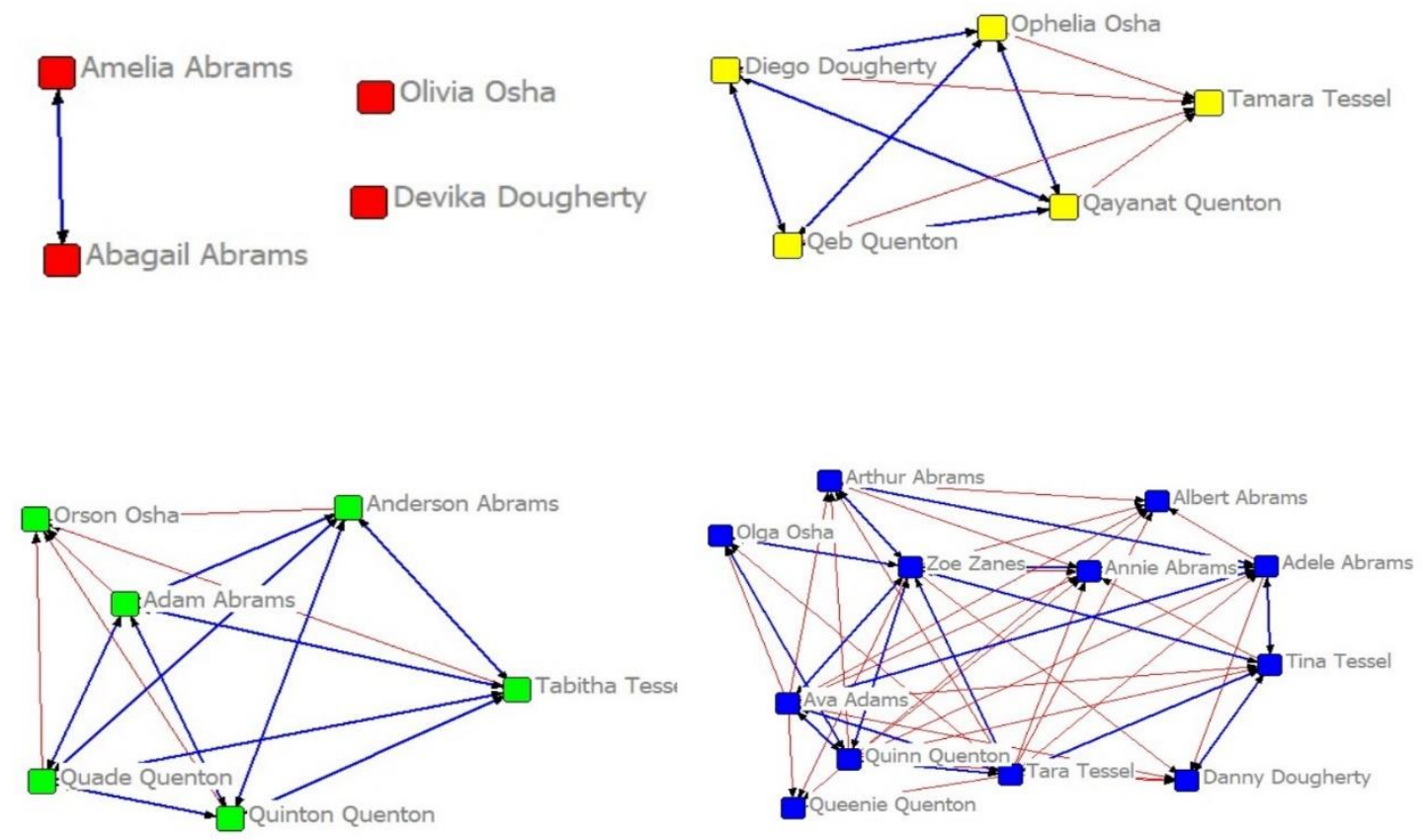
In all conditions, upper classmen appear to be more central in the whole-network sociograms than first and second year participants. When unpacked, fourth year students appear to share the majority of reciprocal ties. Even though some reciprocal times dwindled throughout the semester, in most cases, existing ties remained consistent and more were formed between time 1 and time 2 of data collection. In addition, the majority of participants in each class with recurring reciprocal ties of willingness to rely on each others' competencies were not of the same project teams.

Along with visual representation of the data, QAP correlations were run, and validated the hypothesis that there would be strong, significant $(p=0.0002)$, positive correlations between friendship and all relations during both times of survey data collection.

Initially the strongest correlation was found between task completion and project competence $(r$ $=0.964)$, while the weakest was found between working with the other often and sharing personal problems with the other $(r=0.447)$.

Friendship, at the first time of data collection, indicated moderatley strong correlations between all relations with the exception of working with the other often $\left(r_{1}=0.485\right)$. This demonstrates sufficent evidence to support the hypothesis that the original intra-organizational frienships of this class were not reliant on proximity, but rather, perceptions of competence. Over time, exposure and proximity are assumed to play a role across all relations, as the correlations appear to be noteably stronger.

QAP Correlations

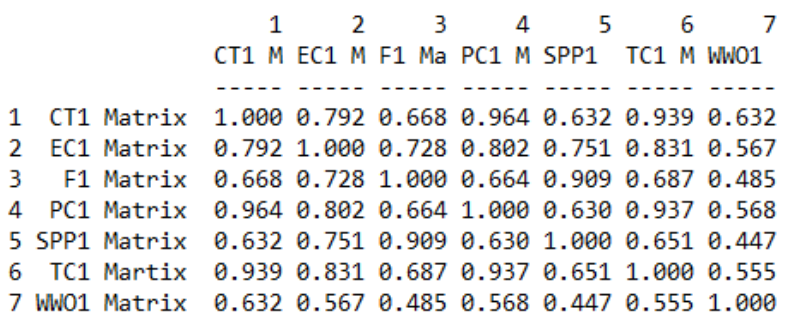

QAP Correlations

$\begin{array}{rrrrrrrrr} & & 1 & 2 & 3 & 4 & 5 & 6 & 7 \\ & & \text { CT2 } & \text { EC2 } & \text { F2 } & \text { PC2 } & \text { PP2 } & \text { TC2 } & \text { WWO2 } \\ 1 & \text { CT2 } & 1.000 & 0.823 & 0.745 & 0.928 & 0.768 & 0.948 & 0.741 \\ 2 & \text { EC2 } & 0.823 & 1.000 & 0.726 & 0.828 & 0.785 & 0.859 & 0.686 \\ 3 & \text { F2 } & 0.745 & 0.726 & 1.000 & 0.742 & 0.843 & 0.752 & 0.797 \\ 4 & \text { PC2 } & 0.928 & 0.828 & 0.742 & 1.000 & 0.757 & 0.965 & 0.723 \\ 5 & \text { PP2 } & 0.768 & 0.785 & 0.843 & 0.757 & 1.000 & 0.776 & 0.674 \\ 6 & \text { TC2 } & 0.948 & 0.859 & 0.752 & 0.965 & 0.776 & 1.000 & 0.738 \\ 7 & \text { WW02 } & 0.741 & 0.686 & 0.797 & 0.723 & 0.674 & 0.738 & 1.000\end{array}$

$$
\begin{gathered}
\mathrm{CT}=\text { Completes Task EC= Ethical Competence } \mathrm{F}=\text { Friendship } \mathrm{PC}=\text { Project Competence } \\
\mathrm{SPP}=\text { Shares Personal Problems } \quad \mathrm{TC}=\text { Technical Competence } \text { WWO = Works With Often } \\
1=\text { Time One } 2=\text { Time Two }
\end{gathered}
$$

\section{Discussion}

The whole-network sociograms for each criteria show patterns of communicative relationships that seem to be tighly knit at the center of the network and that weaken where nodes are located on the edges of the network. Additionally, when isolated into years at the university, the above, unpacked sociograms shows evidence that each separate network depicts a majority of reciprocal 
ties in all relations measuring perceived competencies. The only exception to this are $1^{\text {st }}$ year isolated groups. Due to these findings, it appears that time and level of education play a key role in in-group formation within this particular class. The structure of the network in addition to the patterns of reciprocal ties among in-groups supports the notion that friendship, time spent at the university, and level of education encourage more interaction and higher evaluation of teammates' competencies.

Past research suggests that in-groups that are overly confident in the abilities of their members, or in this case the competencies of their friends, may choose not to seek interactions with outgroups. Similarly, the patterns depicted by the sociograms in this study indicate substantially fewer reciprocal ties to out-group members [6]. This poses a particular issue because, rather than utilizing the strengths of their own team members, participants appear to rely on other participants with shared demographics that are not part of their team. It is highly likely that these misconceptions and behaviors have the potential to delay the progression of projects, as participants are more likely to rely on their in-group members that their teammates, resulting in a poor flow of information and biased information seeking within each team.

In addition, QAP correlations between friendship and all relations support the idea that higher levels of rapport and perception the ability to rely on classmates' competencies predict overall more positive evaluation of other teammates. According to the QAP correlation matrix, the best predictor of perceived competence, both technical and project-specific, is participants'

perception of a teammate's ability to complete tasks. Although seemingly unrelated, there appear to be the strongest correlations between those three relations. Perhaps task completion is related to feelings of trust, as participants felt they could rely on individuals that consistently delivered results. Again, it is evident that feelings of closeness are associated with positive evaluations. Time also appears to play a role in developing these perceptions as the correlations across all relations noticeably increased between data collection periods.

\section{Conclusion}

Granovetter [5] provides evidence that such groups may be enhanced if individuals form wide networks of loose ties rather than narrow networks consisting of potentially biased relationships. This approach would also facilitate the sharing of knowledge and the introduction of new information into the group. Extant research suggests that these two changes would lead to better project outcomes, higher levels of creativity, and a reduction in the potentially harmful group process of groupthink [5]. The SNA approach used in this study offers a productive way to map information flow in such design teams, allowing practitioners and researchers to identify potential barriers to knowledge sharing by illuminating the structural elements of both ideal and emergent information flow. Thus, by finding ways to pinpoint where in-groups begin and end, and what perceptions give them strength, such in-groups can be dismantled, and knowledge sharing may be improved. Practitioners can consider using this knowledge to better monitor and aid teams in identifying their own knowledge sharing patterns - and limitations. As a first step, awareness of the knowledge boundaries that may be perpetuated by the lack of collaboration across design teams in a project setting may help students and instructors to consciously work against the development of these silos. Perhaps a rotation system in which students get to contribute to each of the projects could lead to better use of each student's strengths rather than developing more isolated in-groups that become more and more resistant to seeking outside information. 


\section{References}

[1] J. Methot, J. Lepine, N. Podsakoff, \& J. Christian, (2016). “Are workplace friendships a mixed blessing? Exploring tradeoffs of multiplex relationships and their associations with job performance". Personnel Psychology, 69(2), 311-355.

[2] M. Almeida, \& A. Soares, (2014). "Knowledge sharing in project-based organizations: Overcoming the informational limbo". International Journal of Information Management, 34(6), 770-779.

[3] S. Borgatti, M. Everett, and L. Freeman, 2002. Ucinet 6 for Windows: Software for Social Network Analysis. Harvard, MA: Analytic Technologies.

[4] C.Chiu, M. Hsu, \& E. T. Wang, (2006). "Understanding knowledge sharing in virtual communities: An integration of social capital and social cognitive theories". Decision Support Systems, 42(3), 1872-1888.

[5] M. Granovetter, (1973). "The Strength of Weak Ties," American Journal of Sociology, 78, 1360-1380.

[6] A. Healy, \& J. Offenberg, (2007). "Overconfidence, social groups, and gender: Evidence from the lab and field." http://myweb.lmu.edu/jpate/overconfidence.pdf.

[7] S. Schulz-Hardt, D. Frey, C. Lüthgens, S. Moscovici, \& C. Insko, (2000). "Biased information search in group decision making". Journal of Personality and Social Psychology, 78(4), 655-669.

[8] Y. Zhu, (2016). Solving knowledge sharing disparity: "The role of team identification, organizational identification, and in-group bias". International Journal of Information Management, 36(6), 1174-1183.

[9] C. Zoltowski, W. Oakes , P. Buzzanell, Q. Zhu, M. Kenny Feister (2014). "Defining and assessing engineering ethics in an international context," 2014 IEEE Frontiers in Education Conference (FIE) Proceedings, Madrid, 2014, pp. 1-2.

[10] M. Kenny Feister, C. Zoltowski, P. Buzzanell, D. Torres (2017, June). "Development of Perceptions of Technical and Ethical Expertise In Teams Over Time". Paper presented at 2017 ASEE Annual Conference \& Exposition, Columbus, Ohio. https://peer.asee.org/28175 